\title{
Etiología viral en la neumonía del adulto adquirida en la comunidad en un hospital del sur de Chile
}

\author{
M. LUISA RIOSECO Z. ${ }^{1}$, RAÚL RIQUELME O. ${ }^{1}$, \\ MAURICIO RIQUELME O. ${ }^{1}$, CARLOS INZUNZA P. ${ }^{1}$, PAOLA OYARZÚN G. ${ }^{a}$, \\ YASNA AGÜERO O. ${ }^{a}$, MARCELA FERRÉS G. ${ }^{2}$, PABLO VIAL C. ${ }^{3}$, \\ RODRIGO FASCE P., ${ }^{4, \mathrm{~b}}$, ANTONI TORRES M. ${ }^{5}$
}

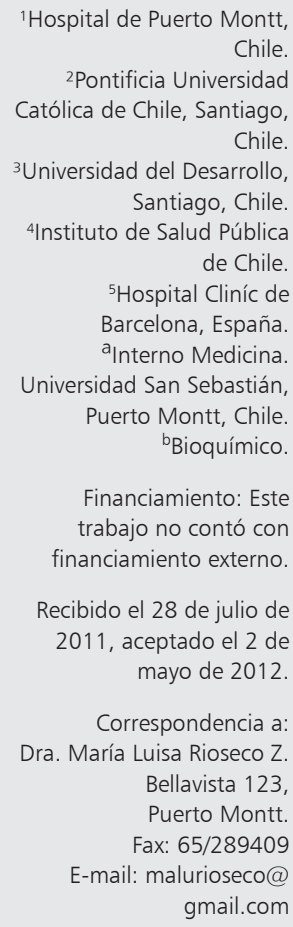
gmail.com

\section{Viral etiology of community acquired pneumonia among adults admitted to a general hospital}

Background: There is paucity of information about viral etiology of community acquired pneumonia in adults. Aim: To investigate the viral etiology of pneumonia among hospitalized patients. Material and Methods: All adults with pneumonia that were hospitalized were prospectively enrolled at Puerto Montt hospital. A microbiological and viral assessment was carried out. Viral assessment included direct immunofluorescence of nasopharyngeal aspirates for influenza $A$ and $B$ virus and serum samples obtained during the acute phase of the disease and during convalescence for Hanta virus. Results: Between April 12005 and March 31 2006, 159 adults aged $62 \pm 20$ years ( $58 \%$ males), were admitted to the hospital for pneumonia. Mean hospital stay was $11.9 \pm 8.6$ days. Four patients had Hantavirus acute infection. Other viruses were identified in twelve patients (7.7\%). Nine had influenza A, one syncytial respiratory virus, one syncytial and influenza $A$ virus and one varicella zoster virus. Excluding patients with Hantavirus, no significant differences in age, clinical presentation, chest $X$ ray findings, laboratory results and mortality were observed between patients with bacterial or viral etiology of the pneumonia. Conclusions: Viral etiology was confirmed in 10\% of adult patients hospitalized with community acquired pneumonia.

(Rev Med Chile 2012; 140: 984-989).

Key words: Hanta virus; Pneumonia; Pneumonia, bacterial; Pneumonia, viral.
$\Lambda$ diferencia de lo que ocurre en la población pediátrica, el estudio de la etiología viral en la neumonía adquirida en la comunidad (NAC) del adulto no es rutinario en la práctica clínica y además, muchas de las neumonías asociadas a virus son secundariamente bacterianas más que primariamente viral, lo que dificulta la real objetivación del problema. Se suma a ello el hecho que las técnicas habituales para la detección de virus tienen baja sensibilidad, especialmente en el adulto ${ }^{1} \mathrm{o}$ entregan resultados en forma re- trospectiva. Por estas razones, existe la impresión de que los virus jugarían un rol relativamente pequeño en la etiología de la NAC del adulto. En los años recientes, la introducción de nuevos métodos diagnósticos como la reacción de polimerasa en cadena (RPC) para varios virus respiratorios ${ }^{2}$ ha permitido mejorar el diagnóstico etiológico de la neumonía revelando que los virus pueden estar presentes como patógenos únicos o asociados a otros agentes en hasta el $50 \%$ de los casos ${ }^{2}$.

El presente trabajo se diseñó con el objetivo 
de investigar el rol de los virus en la etiología de la NAC del adulto que ingresa al Hospital Puerto Montt (HPM) ubicado en el sur de Chile, durante el período de un año.

\section{Material y Método}

Se enrolaron en forma prospectiva y consecutiva los pacientes mayores de 15 años que ingresaron al Servicio de Medicina del HPM entre el $1^{\circ}$ de abril de 2005 y 31 de marzo de 2006 y que cumplían con los criterios diagnósticos para NAC de Fang et al.: infiltrado nuevo y persistente en la radiografía de tórax de admisión y uno o más criterios mayores (tos, expectoración mucopurulenta o hemoptoica, temperatura axilar superior a $37,8^{\circ} \mathrm{C}$ ), o por lo menos dos criterios menores (dolor torácico pleurítico, disnea, compromiso de conciencia, síndrome de condensación en el examen físico pulmonar o recuento de glóbulos blancos (GB) mayor de $12.000 / \mathrm{ml}^{3}$. Se excluyeron pacientes hospitalizados en los últimos 30 días, portadores de VIH, neoplasia activa, neutropenia $(\mathrm{GB}<1.000)$, tratamiento quimioterápico o inmunosupresor en los últimos 6 meses o uso de prednisona $\geq 20 \mathrm{mg} /$ día.

$\mathrm{Al}$ ingreso se realizó un completo registro de historia clínica, examen físico, exámenes de laboratorio y radiografía de tórax.

Se registró si hubo insuficiencia renal aguda (IRA), shock, ambos definidos según criterios publicados $^{4}$, necesidad de Unidad de Cuidados Intensivos (UCI), ventilación mecánica (VM), mortalidad y si ésta pudo ser atribuida a la NAC. Alcoholismo se definió como ingestión estimada $\geq 80$ gramos de alcohol diario el último año. Se realizó una valoración de gravedad al ingreso aplicando el modelo predictivo de Fine y col., que considera edad, sexo, comorbilidad, signos vitales, laboratorio y radiología ${ }^{5}$, el CURB-65 (por siglas en inglés de confusión, uremia, frecuencia respiratoria, presión arterial y edad) ${ }^{6}$ y CRB-65 (donde se excluye la uremia) ${ }^{7}$.

El estudio etiológico bacteriano al ingreso incluyó Gram y cultivo de expectoración en medios de cultivo agar sangre y chocolate en $3 \% \mathrm{CO}_{2}, 2$ baciloscopias de expectoración en sospecha de tuberculosis, 2 hemocultivos (HC) en sistema automatizado BactAlert ${ }^{\circledR}$, estudio de líquido pleural y 2 muestras de sangre (al ingreso y a los 15 días) para estudio serológico de microorganismos atípicos. El suero se mantuvo a $-80{ }^{\circ} \mathrm{C}$ hasta su procesamiento. Las muestras pareadas fueron procesadas mediante inmunofluorescencia indirecta para Mycoplasma pneumoniae (Zeus ${ }^{\circledR}$, New Jersey, U.S.A) y Chlamydophila. pneumoniae (Focus ${ }^{\circledR}$ ). En los pacientes que ingresaron a UCI se buscó antígeno de Legionella pneumophila serogrupo 1 en orina mediante test inmunocromatográfico (NOW Legionella, Binax ${ }^{\circledR}$ ).

El estudio viral incluyó inmunfluorescencia directa (IFD) para virus influenza A (IA) y B, parainfluenza, adenovirus y virus respiratorio sincicial (VRS) en hisopado nasofaringeo y estudio serológico en muestras pareadas para virus IA (H1N1 y H3N2) mediante inhibición de la hemaglutinación en el Instituto de Salud Pública (ISP) de Chile. Además se realizó serología para Hantavirus mediante ELISA (IgG e IgM), usando antígeno recombinante para virus Sin Nombre y Laguna Negra en el Laboratorio de Biología Molecular de la Pontificia Universidad Católica de Chile, (Santiago, Chile). Las muestras positivas fueron confirmadas en el ISP de Chile.

Se consideró diagnóstico de certeza el aislamiento de algún microorganismo patógeno en sangre o líquido pleural, la seroconversión (aumento mayor o igual a 4 veces en el título de IgG en el suero de la fase convaleciente versus aguda), la IFD de hisopado nasofaringeo positiva y la presencia de anticuerpos IgM para virus Hanta. El diagnóstico se consideró probable cuando se aisló un microorganismo patógeno en muestra válida de esputo (más de 25 polimorfonucleares y menos de 10 células epiteliales por campo 40x).

\section{Estadística}

Las variables obtenidas fueron almacenadas y analizadas usando el paquete estadístico SPSS para Windows ${ }^{\circledR}, 10.0$ (SPSS, Chicago, IL, USA). Los resultados son expresados como valores promedio \pm 2 DS. Para comparar las variables continuas se empleó el test $t$ de Student y el test de $\chi^{2}$ o test exacto de Fisher cuando fue apropiado para las variables categóricas. Un valor bilateral de $\mathrm{p}<0,05$ se consideró estadísticamente significativo.

\section{Resultados}

En el período de estudio, ingresaron 159 adultos con NAC. La edad media fue de $62 \pm 20$ años, 
$57 \%$ mayor de 65 años, 57,9\% hombres y permanecieron hospitalizados $11,9 \pm 8,6$ días. El 17\% era de procedencia rural y $5,7 \%$ vivía en casa de reposo. Trece coma dos por ciento había recibido antibióticos en los últimos 15 días y 79,2\% tenía alguna comorbilidad siendo las más frecuentes EPOC o asma (31\%), diabetes (23\%), cardiopatías $(21 \%)$ y alcoholismo (14,5\%). Ingresaron a UCI 25 pacientes $(15,7 \%)$ y 20 $(12,6 \%)$ fueron conectados a VM. Falleció el 13,2 \% (21/159).

Obtuvimos diagnóstico etiológico en 41,5\% (66/159) de los pacientes con un total de 73 microorganismos. Cincuenta pacientes tuvieron etiología bacteriana ( 5 con dos agentes identificados), 15 etiología viral (un caso con IA y VRS) y uno etiología mixta (Streptococcus B-hemolítico grupo A (SBHGA) y varicela) (Tabla 1).

Los exámenes realizados en busca de etiología, la técnica, el rendimiento obtenido y los agentes etiológicos identificados, se muestran en la Tabla 2. De los exámenes dirigidos al diagnóstico viral, el mejor rendimiento se obtuvo con la serología pareada para virus IA que permitió identificar 9 pacientes cuya IFD resultó negativa. La IFD sólo resultó positiva en 3 pacientes, dos con VRS y uno con IA.

Tabla 1. Etiología en 159 adultos con NAC

\begin{tabular}{|lcc|}
\hline & $\begin{array}{c}\text { n de } \\
\text { pacientes }\end{array}$ & $\%$ \\
\hline Streptococcus pneumoniae & 18 & 11,3 \\
\hline Mycoplasma pneumoniae & 13 & 8,2 \\
\hline Influenza A & 9 & 5,7 \\
\hline Chlamydophila pneumoniae & 5 & 3,1 \\
\hline Hantavirus & 4 & 2,4 \\
\hline Escherichia coli & 2 & 1,2 \\
\hline Haemophilus influenzae & 2 & 1,2 \\
\hline Moraxella catharralis & 2 & 1,2 \\
\hline Tuberculosis & 2 & 1,2 \\
\hline Streptococcus Grupo A & 1 & 0,6 \\
\hline VRS & 1 & 0,6 \\
\hline VRS e influenza A & 1 & 0,6 \\
\hline Varicela y Streptococcus Grupo A & 1 & 0,6 \\
\hline Streptococcus mitis y M. pneumoniae & 1 & 0,6 \\
\hline S. aureus y Citrobacter freundii & 1 & 0,6 \\
\hline S. aureus y Klebsiella pneumoniae & 1 & 0,6 \\
\hline M. pneumoniae y H. influenzae & 1 & 0,6 \\
\hline M. pneumoniae y S. pneumoniae & 1 & 0,6 \\
\hline Desconocida & 93 & 58,5 \\
\hline
\end{tabular}

Hubo 4 casos de síndrome cardiopulmonar por Hantavirus (SCPHV), 3 con serología $\operatorname{IgM}(+)$ e $\operatorname{IgG}(-)$ y 1 caso $\operatorname{IgM}(+)$ e $\operatorname{IgG}(+)$. Hubo 3 casos graves, 1 moderado y uno falleció. Se detectaron dos pacientes con serología $\operatorname{IgM}(-)$ e $\operatorname{IgG}(+)$ sin antecedente sugerente de SCPHV. Excluyendo los 4 casos activos, se obtuvo una seroprevalencia de Hantavirus de 1,3\% (2/155). Todos los casos de SCPHV tenían compromiso radiológico extenso bilateral, principalmente intersticial. Comparados con los otros casos de NAC, tenían con mayor frecuencia plaquetas $<100.000(\mathrm{p}=0,000)$, hiponatremia $<135 \mathrm{mEq} / \mathrm{L}(\mathrm{p}=0,011)$, ninguno tenía esputo $(\mathrm{p}=0,002)$, las imágenes radiográficas progresaron más del 50\% en $48 \mathrm{~h}(\mathrm{p}=0,024)$, tuvieron con mayor frecuencia IRA $(\mathrm{p}=0,009)$, PAFI $<200(\mathrm{p}=0,008)$, shock $(\mathrm{p}=0,005)$, requirieron $\mathrm{UCI}(\mathrm{p}=0,011)$ y $\mathrm{VM}$ $(p=0,006)$. El recuento de plaquetas en los pacientes con SCPHV fue significativamente menor $(44.750 \pm 30.630$, rango $14.000-87.000$ vs $243.508 \pm 129.867$, rango 9.760-705.000; $\mathrm{p}=0,003)$ y el hematocrito significativamente mayor $(51,7 \pm 7,2$, rango $44,1-61,5$ vs $37,5 \pm$ 6,7 rango $18-51 ; p=0,000$ ), pero esto no se correlacionó con mortalidad. En todos los pacientes con SCPHV hubo sospecha etiológica previa al resultado de la serología en base a antecedentes epidemiológicos, radiología, hematocrito elevado y/o plaquetas bajo 100.000 . No hubo casos con sospecha clínica de SCPHV no confirmada.

Excluyendo los pacientes con SCPHV, en los 155 pacientes restantes pudimos identificar 12 NAC (7,7\%) asociadas a virus: 9 casos de IA, un caso por VRS, un caso con IA y VRS e incluimos un paciente que tenía una varicela extensa y neumonía grave y que además tuvo HC positivos a SBHGA.

No se encontraron diferencias significativas en la edad, presentación clínica, radiológica, de laboratorio, en la evolución ni en la mortalidad de aquellos con 
Etiología viral en NAC - M. L. Rioseco et al

Tabla 2. Estudio etiológico en 159 adultos con NAC

\begin{tabular}{|c|c|c|c|c|c|}
\hline Test diagnóstico & Metodología & $\begin{array}{c}\mathbf{n}(\%) \\
\text { pacientes }\end{array}$ & $\begin{array}{c}\text { Rendimiento } \\
(\%)\end{array}$ & \multicolumn{2}{|c|}{ Agente etiológico (n) } \\
\hline Hemocultivos & Bact Alert ${ }^{\circledR}$ & $146(92,4)$ & 13 & $\begin{array}{l}\text { S. pneumoniae } \\
\text { E. coli } \\
\text { S. pyogenes } \\
\text { S. mitis }\end{array}$ & $\begin{array}{r}(15) \\
(2) \\
(1) \\
(1)\end{array}$ \\
\hline Cultivo expectoración & $\begin{array}{l}\text { Cultivo corriente en } \\
\text { muestra válida }\end{array}$ & $65(40,9)$ & 21,5 & $\begin{array}{l}\text { S. pneumoniae } \\
\text { H. influenzae } \\
\text { M. catharralis } \\
\text { S. aureus } \\
\text { E. coli } \\
\text { K. pneumoniae } \\
\text { C. freundii }\end{array}$ & $\begin{array}{l}\text { (4) } \\
(3) \\
(3) \\
(2) \\
(1) \\
(1) \\
(1)\end{array}$ \\
\hline Cultivo líquido pleural & Cultivo corriente & 1 & 100 & S. pneumoniae & (1) \\
\hline $\begin{array}{l}\text { Panel viral en hisopado } \\
\text { nasofaringeo }\end{array}$ & $\begin{array}{l}\text { Inmunofluorescencia di- } \\
\text { recta }(I A, I B, V R S, A D V, P I)\end{array}$ & $120(75,5)$ & 2,5 & $\begin{array}{l}\text { VRS } \\
\text { Influenza A }\end{array}$ & $\begin{array}{l}(2) \\
(1)\end{array}$ \\
\hline $\begin{array}{l}\text { Serología pareada Mycoplasma } \\
\text { pneumoniae (lgG) }\end{array}$ & Microinmunofluorescencia & $102(64,2)$ & 17,6 & M. pneumoniae & (18) \\
\hline $\begin{array}{l}\text { Serología pareada Chlamydophila } \\
\text { pneumoniae (IgG) }\end{array}$ & Microinmunofluorescencia & $100(62,9)$ & 5,0 & C. pneumoniae & (5) \\
\hline $\begin{array}{l}\text { Antígeno urinario Legionella } \\
\text { pneumophila }\end{array}$ & Inmunocromatografía & $13(8,2)$ & 0 & & \\
\hline Serología Hantavirus (IgM e lgG) & ELISA & $157(98,7)$ & 2,5 & $\begin{array}{l}\lg M(+) \lg G(-) \\
\lg M(+) \lg G(+)\end{array}$ & $\begin{array}{l}(3) \\
(1)\end{array}$ \\
\hline Serología pareada IA e IB & $\begin{array}{l}\text { Inhibición de hemagluti- } \\
\text { nación }\end{array}$ & $101(63,5)$ & 8,9 & IA H3N2 & (9) \\
\hline Baciloscopia & Ziehl Nielsen & $2(1,3)$ & 100 & M. tuberculosis & (2) \\
\hline
\end{tabular}

neumonía viral comparados con los pacientes en que se demostró etiología bacteriana. Tampoco hubo diferencias al evaluar la gravedad al ingreso mediante los criterios PSI, CRB-65 y CURB-65.

La hospitalización fue más prolongada en los que ingresaron a UCI $(17,2 \pm 12,6$ vs $10,9 \pm 7,2$ días, $\mathrm{p}=0,001)$ y en los que requirieron $\mathrm{VM}(16,7$ $\pm 13,6$ vs $11,9 \pm 8,6$ días, $p=0,008)$ independiente de la etiología.

El 58,5\% del total de los pacientes correspondió a los grupos PSI IV y V (93/159) y el $26,4 \%$ tuvo CURB-65 3 a 5. La mortalidad en el grupo PSI V fue de $48 \%$.

Fallecieron 21 pacientes $(13,2 \%)$ y de ellos el $71,4 \%(15 / 21)$ lo hizo antes de trascurrir 15 días desde el ingreso. Factores asociados a mortalidad fueron: PSI IV-V (19,3 vs 4,5\% OR 5,4 IC95\% 1,4$17,9, \mathrm{p}=0,000)$, CURB-65 3-5 (40,5 vs 3,4\%, OR 19,2 IC95\% 5,9-62, p = 0,000), CRB-65 3-4 (45 vs
$8,6 \%$, OR 8,7 IC95\% 3-25 p = 0,000), VM (62 vs $5 \%$, OR 30 IC $95 \%$ 9,5-97,3, $\mathrm{p}=0,000)$. No hubo asociación entre etiología y mortalidad.

\section{Conclusiones}

Los principales hallazgos del estudio son mostrar que los virus, particularmente IA, son importantes agentes etiológicos en la NAC del adulto y que la presentación clínica, con la excepción del Hantavirus, fue indistinguible de las NAC de origen bacteriano.

El SCPHV, en la medida que se manifiesta por un cuadro febril asociado a infiltrados pulmonares cumple con la definición de NAC, sin embargo, creemos debe ser considerado en forma separada. El SCPHV es una zoonosis endémica en el sur de Chile y si se toman en cuenta los antecedentes 
epidemiológicos de ruralidad y algunos elementos clínicos y de laboratorio básico como el recuento de plaquetas y el hematocrito, se puede obtener un diagnóstico presuntivo con facilidad ${ }^{8}$, lo que no ocurre con los virus respiratorios más frecuentes. El diagnóstico de 4 casos en un año y la seroprevalencia de $1,3 \%$ para Hantavirus en adultos que se hospitalizan por NAC en Puerto Montt, reflejan nuestra particular realidad endémica y geográfica.

La introducción del diagnóstico viral en este estudio, permitió mejorar la capacidad diagnóstica en un porcentaje importante respecto a una serie local anterior, donde la etiología sólo se demostró en $29,5 \%$ de los pacientes con $\mathrm{NAC}^{9}$. Sin embargo, el mejor rendimiento lo obtuvimos con la serología pareada para IA, técnica laboriosa, no disponible en hospitales y que entrega diagnóstico retrospectivo con utilidad epidemiológica. La incorporación de la PCR permitiría elevar el 41,5\% actual a valores muy superiores.

Es un hecho conocido que entre los virus respiratorios, IA es el más frecuentemente involucrado en la etiología de la NAC, pero también se pueden reconocer con alguna frecuencia otros virus comunes como el VRS, adenovirus, parainfluenza y otros como metapneumovirus, herpes simplex y varicella zooster ${ }^{10}$.

La introducción reciente de mejores métodos diagnósticos como la amplificación de ácido nucleico, ha mejorado la capacidad de detectar distintos virus en la fase aguda de la enfermedad. Con esta herramienta diagnóstica se ha podido establecer la causa viral en más de $50 \%$ de los pacientes con $\mathrm{NAC}^{2,11}$ pero desde el punto de vista clínico, no hay claros elementos que permitan diferenciarlas de la NAC bacteriana. El virus IA causa brotes de intensidad variable cada invierno, produciendo morbimortalidad especialmente en ancianos. El VRS puede afectar hasta el 3-7\% de ancianos sanos y hasta el $4-10 \%$ de adultos de alto riesgo (con enfermedades cardiacas y respiratorias crónicas) y ocurre neumonía en 2-7\% de las personas infectadas ${ }^{12}$.

En Chile hay escasa información sobre el rol de los virus en la NAC del adulto. Díaz et al., en 130 pacientes con NAC en que se usó IFD en hisopado nasofaríngeo para influenza A y B, parainfluenza 1 a 3 , adenovirus y VRS, obtuvo un rendimiento de $25 \%$, identificando principalmente virus parainfluenza 1-3 (14 casos) seguido de IA ( 8 casos $)^{13}$. Nosotros, pese a usar similar técnica, no pudimos reproducir estas cifras. Sólo obtuvimos un rendimiento de 2,5\% para la IFD y dado que usualmente los test diagnósticos que detectan antígeno viral tienen mayor rendimiento en los primeros días de evolución, creemos posible que esta diferencia de rendimiento podría estar reflejando diferencias en el momento de hospitalización entre un hospital universitario de alta complejidad y las latencias propias de un hospital público de provincia.

Por otra parte y producto de exposiciones previas, los adultos tienen anticuerpos medibles, razón por la que una muestra aislada de IgG no es útil como método diagnóstico. La elevación más de cuatro veces del valor basal de IgG es un buen método de investigación epidemiológica ${ }^{11} \mathrm{y}$ nos permitió demostrar 9 casos de IA que clínicamente nunca fueron sospechados ni recibieron tratamiento antiviral. Debe considerarse que este método diagnóstico pudo subestimar la presencia de agentes etiológicos en los pacientes más graves ya que en $71,4 \%$ de los fallecidos no se obtuvo la segunda muestra de suero por haber fallecido antes de los 15 días.

Nuestro trabajo aporta al conocimiento de la participación de los virus en la NAC del adulto en nuestro medio y señala la necesidad con contar con estudios rutinarios de mayor sensibilidad, especificidad y rapidez que permitan tratar oportunamente estos casos que muchas veces no son sospechados ni diagnosticados. Al respecto, la implementación de la RPC en varios hospitales del país como consecuencia de la pandemia por H1N1 en el año 2009, permitiría disponer de esta técnica para otros virus respiratorios, mejorando así la oportunidad diagnóstica y el manejo de pacientes hospitalizados por NAC. El conocer precozmente la etiología viral permite iniciar la terapia específica con inhibidores de la neuroaminidasa en el caso de los virus influenza, limitar el uso innecesario de antimicrobianos e implementar medidas específicas para evitar la transmisión nosocomial de estos agentes.

\section{Referencias}

1. CDC. Evaluation of rapid influenza diagnostic tests for detection of novel influenza A (H1N1) virus - United States, 2009. MMWR 2009; 58 (No30).

2. Marcos MA, Esperatti M, Torres A. Viral pneumonia. Curr Opin Infect Dis 2009; 22: 143-7. 
Etiología viral en NAC - M. L. Rioseco et al

3. Fang G, Fine M, Orloff J, Arisumi D, Yu VL, Kapoor $\mathrm{W}$, et al. New and emerging etiologies for community acquired pneumonia with implications for therapy: A prospective multicenter study of 359 cases. Medicine 1990; 69: 307-16.

4. American College of Chest Physicians Society of Critical Care Medicine consensus conference committee. Definitions for sepsis and organ failure and guidelines for the use of innovatives therapies in sepsis. Critical Care Med 1992; 20: 864-73.

5. Fine M, Auble T, Yealy D, Hanusa BH, Weissfeld LA, Singer DE, et al. A prediction rule to identify low-risk patients with community-acquired pneumonia. N Engl J Med 1997; 336: 243-50.

6. Lim WS, van der Eerden MM, Laing R, Boesma WG, Karalus N, Town GL, et al. Defining community acquired pneumonia severity on presentation to hospital: an international derivation and validation study. Thorax 2003; 58: 377-82.

7. Lim WS, Baudouin SV, George RC, Hill AT Jamieson C, Le Jeune I, et al. BTS guidelines for the management of community acquired pneumonia in adults: update 2009.
Thorax 2009; 64 Suppl 3: iii1-55.

8. Riquelme R, Riquelme M, Torres A, Rioseco ML, Vergara J, Scholz L, et al. Hantavirus Pulmonary Syndrome, Southern Chile. Emerg Infect Dis 2003; 9 Nº11: 1438-43.

9. Riquelme R, Riquelme M, Rioseco ML, Gómez V, Gil R. Neumonía adquirida en la comunidad en Puerto Montt. Etiología. Rev Chil Enf Resp 2003; 19: A276.

10. Mandell L, Wunderink R, Anzueto A, Bartlett, Campbell G, Dean N, et al. Infectious Diseases Society of America/ American Thoracic Society Consensus Guidelines on the Management of Community-Acquired Pneumonia in Adults. CID 2007; 44 (Suppl 2): 27-72.

11. Marcos MA, Esperatti M, Torres A. Viral pneumonia. Curr Opin Infect Dis 2009; 22: 143-7.

12. Falsey A, Hennessey PA, Formica MA, Cox C, Walsh EE. Respiratory syncitial virus infection in elderly and highrisk adults. N Engl Med 2005; 352: 1749-59

13. Díaz A, Fuentes G, Couble C, Uribe R, Mercado G, Soza A, et al. Etiología de la neumonía adquirida en la comunidad en adultos hospitalizados en Santiago, Chile: implicancias para las guías clínicas. Rev Chil Enf Respir 2005; 21: 23-32. 